\title{
Evaluating Collaboration Networks in Higher Education Research
}


Denise Leite • Isabel Pinho

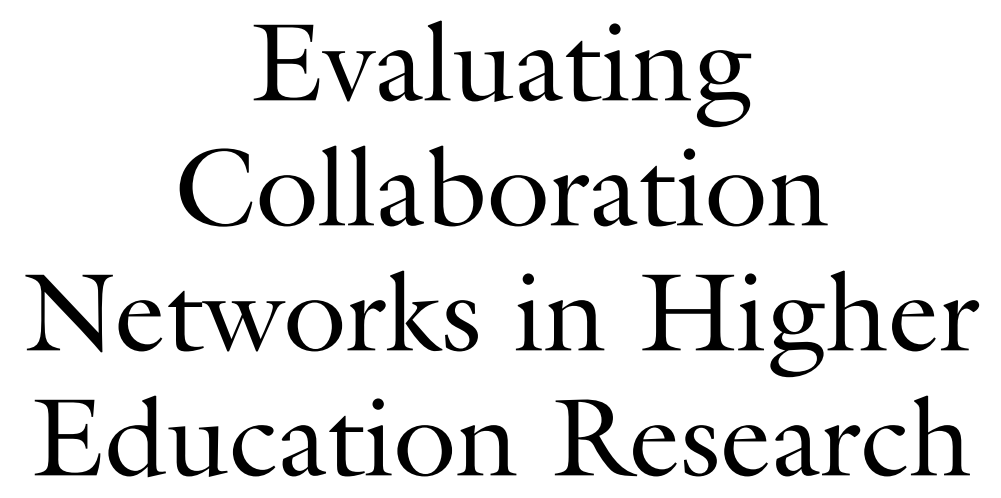

Drivers of Excellence 
Denise Leite

Federal University of Rio

Grande do Sul

Porto Alegre,

Rio Grande do Sul, Brazil
Isabel Pinho

University of Aveiro

Aveiro, Baixo Vouga, Portugal

ISBN 978-3-319-45224-1

DOI $10.1007 / 978-3-319-45225-8$

ISBN 978-3-319-45225-8 (eBook)

Library of Congress Control Number: 2016950013

(C) The Editor(s) (if applicable) and The Author(s) 2017

This book was advertised with a copyright holder in the name of the publisher in error, whereas the author holds the copyright.

This work is subject to copyright. All rights are solely and exclusively licensed by the Publisher, whether the whole or part of the material is concerned, specifically the rights of translation, reprinting, reuse of illustrations, recitation, broadcasting, reproduction on microfilms or in any other physical way, and transmission or information storage and retrieval, electronic adaptation, computer software, or by similar or dissimilar methodology now known or hereafter developed.

The use of general descriptive names, registered names, trademarks, service marks, etc. in this publication does not imply, even in the absence of a specific statement, that such names are exempt from the relevant protective laws and regulations and therefore free for general use. The publisher, the authors and the editors are safe to assume that the advice and information in this book are believed to be true and accurate at the date of publication. Neither the publisher nor the authors or the editors give a warranty, express or implied, with respect to the material contained herein or for any errors or omissions that may have been made.

With the collaboration of Bernardo S. Miorando and Cláudia Pinho Cover illustration: Détail de la Tour Eiffel @ nemesis2207/Fotolia.co.uk

Printed on acid-free paper

This Palgrave Macmillan imprint is published by Springer Nature The registered company is Springer International Publishing AG

The registered company address is: Gewerbestrasse 11, 6330 Cham, Switzerland 
In Memoriam Rui Santiago

With him we built networks across the Atlantic 


\section{Preface}

Once, years ago, an american writer said that autonomy was not exactly a condition for democracy: the reverse would be absolutely true. Without participation in what is important to welfare, without the right to engage in the decision-making process, we are no more than incomplete humans in a system that decides for us. "Freedom, justice, equality, and autonomy are all products of common thinking and common living; democracy creates them" (Barber, 1984, p. xv). Our deepest values, participation, and autonomy, lying in the foundations of our academic work, were expressed in the realization of this book. In this direction, both of us, the authors, were researching, separated by an ocean of distance. In common, we have the same research theme-networks.

When we think about the origin of this book, we remember the moments of intense intellectual activity in a conference, sponsored by an association that for over half a century stimulated democracy and free participation of academics and students. Why democracy? The answer can be, simply, the following: in this event we, the intellectuals, propose the themes for a panel and submit them to our peers. Once reviewed and accepted, we present our articles and research in discussion groups. This event mobilizes academic and personal relations among researchers from many countries and institutions creating new networks. This book comes to light in such way, with one Latin American author and one European author. Both have had equal opportunities for participation based on organizational democracy conditions. At the Lasa Conference, we were in separate rooms, different groups, presenting the same theme-research 
networks. An international publisher had shown interest in the publication of the theme. Invitations were made and the challenge was accepted.

The book's intention and scope derived from a demand for understanding what roles research networks evaluation has in higher education. Our starting point is that research networks can be workspaces where autonomy and democracy arise characterized by collaboration among different people. The individuals who form a network keep differences in academic background, hierarchical position, and field of expertise. We propose in this book that networks must be evaluated, or, in other words, network leaders must make wise decisions aligning goals and accomplishments with a focus on excellence, producing knowledge, in order to achieve the best results and excellence of products. To focus in the direction of excellence, networks' self-evaluation, with the participation of network members, is a driver. To achieve this, we have identified, in the literature and in our research practices, qualitative and quantitative indicators that we explore in this work.

We argue that evaluation goes beyond a qualified organizer. Evaluation indeed organizes data and provides information that can be used for improving performance in groups. But the data can be questioned according to different perspectives. Thus, by proposing a new evaluation format, we emphasize a rich research activity, considering the network as a facilitator learning space, a context for education, and for training new researchers. We understand network as a self-governing productive agency for its members, a creative environment for research where it is possible to develop new methodologies and technological issues. It can be a place of innovation with continuous improvement in research processes to produce and exchange knowledge. It is important to note that the literature reviewed showed that there is a lack of studies on the theme of evaluating collaboration networks in higher education.

The chapters of this book come as a result from values that we consider fundamental and profess in our academic praxis. Technically, they are written results of research projects integration, supported by $\mathrm{CNPq}$, the National Council for Scientific and Technological Development of Brazil, namely Evaluation and Collaborative Networks I: Innovation and Changes in the Webs of Knowledge (Leite, D., Research Project, CNPq Ufrgs RS, 2010); Evaluation and Collaborative Networks II: Scientific Production in the Field of Education and the International Science Control (Leite, D., Research Project, CNPq, Ufrgs, 2015); Higher Education Evaluation and Innovation Policies: Impacts on Knowledge Production (Lima, Elizeth; 
Research Project, CNPq Unemat Mt, 2012); and a postdoctoral study on Collaborative Networks, a Literature Review (Pinho, I., Research Project, $\mathrm{CNPq} \mathrm{Br}$, and University of Aveiro Pt, 2013).

The themes of the chapters presented here were selected from those named research projects. They were gestated in practices and experiences integrated by relationships among members of a 25-year research group. The networks were woven with colleagues and students and technicians from the same region, later on branched out into many networks through coauthorships. Uruguayan, Argentinean, Chilean, Mexican, and Colombian researchers, as well as European researchers, mainly Portuguese, were among coauthorship relations that inspired this book.

In conclusion, this intellectual work humbly acknowledges that we were not alone. There were many people who-knowingly or unknowinglywere responsible for building ideas that are explored in this book. Thus, we wish to thank the colleagues of InovAval Research Group, our partners Maria Elly Herz Genro, Célia Elizabeth Caregnato, Elizeth Lima, and Sonia Caregnato from whom we are always learning. Very special thanks goes to Bernardo Sfredo Miorando, doctorate student from UFRGS and Cláudia Pinho, University of Aveiro. They have been our gentle counselors for the English linguistic revision and bibliographical references; we are grateful for their attentive reading of the manuscript, suggestions, and incentives. We apologize to our students, masters, and doctorates from Ufrgs and Unemat, who understood we could not give them more attention during the time we were writing. We are pleased to offer this book in memory of Prof. Dr. Rui Santiago. His generosity as a person and knowledge as a professor motivated durable relationships, permanent networks, and creative exchanges. Finally, we would like to acknowledge Palgrave's invitation to publish this book and detach the positive and critical appraisal of anonymous reviewers of the first manuscript.

We, the authors, sincerely hope that this work contributes to relevant research supported by a comprehensive format of self-evaluation. We consider the participatory format of evaluation as a driver for excellence. We have the intention to propose a new perspective on network studies. We want to go beyond the sum of individual productivity where each researcher is ranked by a productivistic dimension. We hope that the evaluation of research and collaboration networks will be referred to as the engines that move the collective responsibility for the greatest and humanistic achievements in science at the age of globalization. 
In times of accelerated connectivity and information, knowledge production supported by strong research is a channel for the development of nations, being credited to the global economy. Not pretentiously, this book aims at collaborating with the perspective of a connected world, the connected context of global science. It intends to be showing how crucial the understanding of research networks' international links is. As we assume, a network can be weaved around the art of generating and producing knowledge, rigorous research methodologies, and consequently, improving better performance and impact. We understand that it is around a simple microstructure, similar to the one of a research network, in which knowledge is alive and can be delivered and used. It can thus be helpful in taking a closer look at the inside (and in site) of a research network, trying to capture its functioning standards, as well as in taking a look at the direction of social relations among researchers and partners and to perceive how many interaction processes can build a single research product or an unpretentious result.

We sincerely hope that this book will be useful to all readers. We wish everyone a generous, fruitful, and inspiring reading as pleasant as it was for us to write the pivot-style book.

Federal University of Rio Grande do Sul, Brazil

Denise Leite University of Aveiro, Portugal, Isabel Pinho Autumn (South) and Spring (North)

March 2016 


\section{Contents}

1 Science Geography and International Research Collaboration

2 Limits and Frontiers to International Collaboration

3 Theoretical Approaches to Research Collaboration Networks

4 Research Collaboration Networks: What Do Researchers Say and What Networks Show?

5 What Do We Measure by Evaluating Research Collaboration Networks?

6 What Is RNPE Evaluation? Does Metrics Mean the Same? 79

7 Concluding Remarks: Evaluation and Collaboration

References

Index 


\section{List of Figures}

Fig. 1.1 Changing role of the four world regions in major fields of science publications and citations

Fig. 1.2 Research performance framework

Fig. 4.1 Coauthorship articles 2001-2010 from Brazil (PE, SSHEd) and Portugal (SSH)

Fig. 4.2 Coauthorship network RBBIO: 2004-2013

53

Fig. 5.1 University of Aveiro U-Multirank performance profile

Fig. 5.2 Measure of impact 


\section{LisT OF TABLES}

Table 3.1 Types of collaboration $\quad 38$

Table 4.1 Research group RBBIO case study $\quad 51$

Table 5.1 Values and quality assessment $\quad 60$

Table 5.2 Top ten indicators employed by the national and global ranking systems 61

Table 5.3 Indicators classification $\quad 62$

Table 5.4 Impact indicators: Leiden ranking $\quad 64$

Table 5.5 Collaboration indicators: Leiden ranking 65

Table 5.6 CWTS standard bibliometric indicators 69

$\begin{array}{lll}\text { Table 5.7 Article-Level metrics tools } & 70\end{array}$

Table 5.8 Leiden manifesto ten principles $\quad 76$

$\begin{array}{lll}\text { Table 6.1 Protocol for analysis of collaboration in articles } & 91\end{array}$

Table 6.2 Micro-level quantitative indicators for RNPE 93

Table 6.3 Micro-level qualitative indicators for RNPE 96 